\title{
EXPERIMENTAL STUDY AND DESIGN OF FLAT BELT CONVEYER SYSTEM WITH DIFFERENT R.P.M.
}

\author{
Vishnu Datta Tiwari ${ }^{1}{ }^{凶}$, Prof. Gouraw Beohar ${ }^{2}$ \\ ${ }^{1}$ MTech Student (Machine Design), Shri Ram Institute of Technology, Jabalpur (M.P.), India \\ 2 Professor, Shri Ram Institute of Technology, Jabalpur (M.P.), India
}

DOI: https://doi.org/10.29121/ijetmr.v7.i12.2020.845

Article Citation: Vishnu Datta Tiwari, and Prof. Gouraw Beohar. (2020). EXPERIMENTAL STUDY AND DESIGN OF FLAT BELT CONVEYER SYSTEM WITH DIFFERENT R.P.M.. International Journal of Engineering Technologies and Management Research, 7(12), 67-73.

https://doi.org/10.29121/ijetmr.v7 .i12.2020.845

Published Date: 31 December 2020

Keywords:

Flat Belt

Different Speed

Roller

Load Carrying Capacity

\begin{abstract}
In this work, we are studying during experiments with a flat belt conveyor system with different speeds such as 30,60,90, 120 and 150 R.P.M. In this study, it is also included that the observations of the different load capacities (Grams) at different outlet times (Hours). The design of the flat belt conveyor system is very important for the specific speed range of the material handling system from place to place, which depends on the effective length of the belt.
\end{abstract}

\section{INTRODUCTION}

The flat belt conveyor system is very useful for the material handling system because it has different speeds from the gear head D.C. motor, such as 30,60, 90, 120 and 150 R.P.M. The transport system is also very important when two industrial units were built in different selective locations, so the material handling system is very necessary for the proper functioning of the plants.

\section{LITERATURE REVIEW}

Miroslav Bajda and Robert Krol, (2015) The means of transport commonly used in the Polish mining industry are belt conveyors, which have eliminated the cyclical transport previously used in most industries. The range of applications and differentiations resulting from the profile of the mining activity, requires the design and production of components of belt conveyors with the greatest care. Breaks or limitations in the mass flow carried, forced by individual elements of the belt conveyor, directly reduce the effectiveness of the entire technological system. Thus, already in the design phase of belt conveyors, optimization attempts are made, aimed primarily at reducing energy consumption. 
Deepak Tarbada et.al, (2017) Handling involves moving materials from one location to another for the purpose of processing or storage. According to the American Material Handling society, 'Material Handling is an art and science of involving the movement, packaging and storage of subsystems in any form. Thus, the material handling function includes all types of vertical, horizontal movements or a combination of both and all types of fluid, semifluid and discrete and movement items required for packaging and storage. The material handling function is considered one of the most important activities of the production function in relation to the total time spent by the materials within the factory area.

\section{RESEARCH METHODOLOGY}

The resistance of the belt bearing on the pulleys results from the cyclic compression of the lower side cover plate by the transport pulleys. After leaving the roller, the belt returns to its original shape with the delay resulting from the loss of attenuation of the cover plate material. It causes the conversion of part of the kinetic energy of the belt bearing to thermal energy. Based on the analysis of research studies on the phenomena that occur on the belt during the operation of the conveyor, that is, dumping and friction in connection with the periodic deformation process of the belt.

\section{PROPOSED METHODOLOGY}

4.1 Reading the previous research paper

4.2 Finding the research gap in related papers

$4.3 \mathrm{We}$ are selected the experimental process

4.4 Data found from run of test rig

4.5 Found the optimum position during the operating of test rig.

\section{EXPERIMENT PROCEDURES}

The gear head motor, the power supply based on the step-down transformer, the cylindrical roller and the structure are used in the construction of the working model. In the flat belt system, it is very useful for the material handling system from place to place, because it has different types of motor speed, such as 30, 60, 90, 120 and 150 R.P.M. with different load capacity in grams at different working times such as 1 to 10 hours.

Table 1: Specification of components

\begin{tabular}{|c|c|c|}
\hline Sr. No. & Components & Specification \\
\hline 1 & Gear head Motor & 12V.D.C., 10Kgf Torque \\
\hline 2 & Power supply & 12V.D.C., Transformer and Rectifier based with 5 Amp. \\
\hline 3 & Roller & Cylindrical Type \\
\hline 4 & Frame & Metallic Type \\
\hline
\end{tabular}

Table 2: Dimension of Angled metallic frame 25.4X $25.4 \mathrm{~mm}$

\begin{tabular}{|c|c|c|}
\hline Sl. No. & Name & Magnitude in $\mathrm{mm}$ \\
\hline 1 & Length & 760.24 \\
\hline 2 & Width & 380.68 \\
\hline 3 & Height & 520.87 \\
\hline
\end{tabular}

Table 3: Dimension of Belt

\begin{tabular}{|c|c|c|}
\hline Sl. No. & Name & Magnitude in $\mathrm{mm}$ \\
\hline 1 & Effective Length & 1002.34 \\
\hline 2 & Width & 103.65 \\
\hline 3 & Thickness & 1.02 \\
\hline
\end{tabular}


Table 4: Dimension of Roller and Shaft

\begin{tabular}{|c|c|c|}
\hline Sl. No. & Name & Magnitude in $\mathrm{mm}$ \\
\hline 1 & Outer diameter of roller & 75.33 \\
\hline 2 & Inner diameter of roller & 5.88 \\
\hline 3 & Outer diameter of shaft & 5.21 \\
\hline
\end{tabular}

Table 5: Dimension of Inlet

\begin{tabular}{|c|c|c|}
\hline Sl. No. & Name & Magnitude in $\mathrm{mm}$ \\
\hline 1 & Outer diameter & 68.85 \\
\hline 2 & Thickness & 1.22 \\
\hline
\end{tabular}

Table 6: Dimension of Outlet

\begin{tabular}{|c|c|c|}
\hline Sl. No. & Name & Magnitude in $\mathrm{mm}$ \\
\hline 1 & Outer diameter & 115.35 \\
\hline 2 & Thickness & 2.16 \\
\hline
\end{tabular}

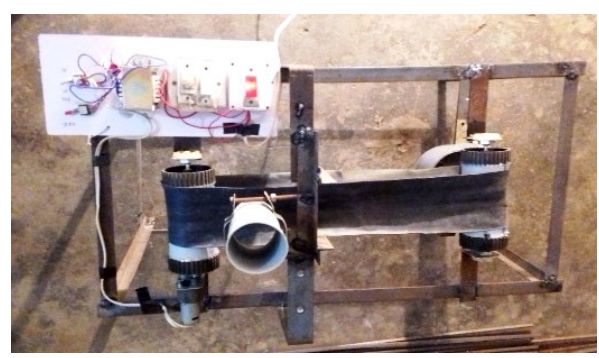

Figure 1: Experimental setup

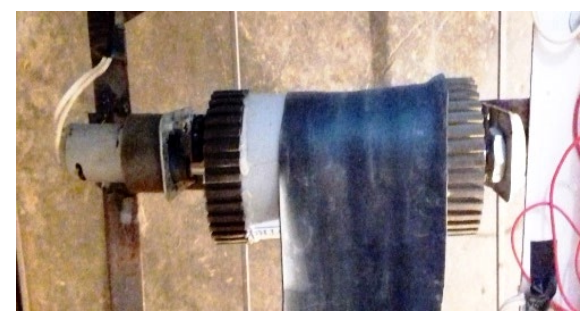

Figure 2: Inlet belt derive system

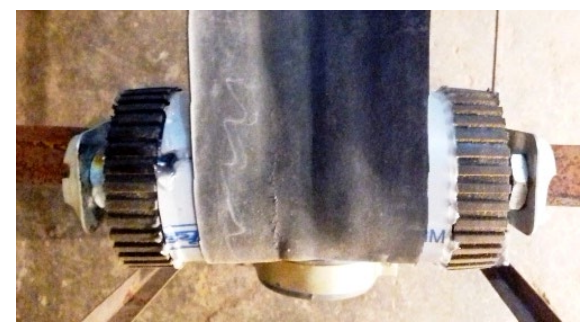

Figure 3: Outlet belt derive system

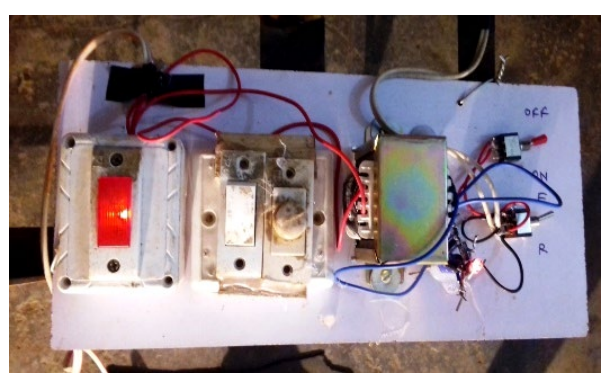

Figure 4: Control panel systems 
Experimental Study and Design of Flat Belt Conveyer System with Different R.P.M.

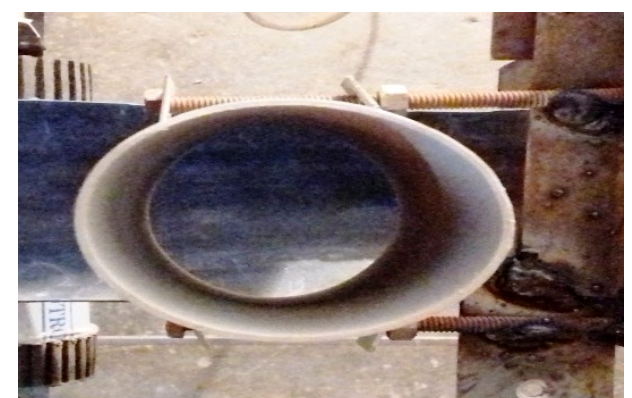

Figure 5: Inlet material feeding system

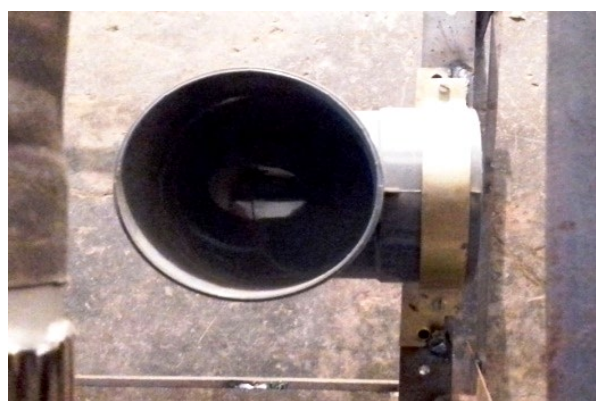

Figure 6: Outlet material delivery system

\section{RESULTS AND DISCUSSION}

Table 7: Gear head D.C. Motor with 30 R.P.M.

\begin{tabular}{|c|c|c|}
\hline Observation No. & Time (Minutes) & Load carrying capacity (Grams) \\
\hline 1 & 1 & 500 \\
\hline 2 & 2 & 1000 \\
\hline 3 & 3 & 1500 \\
\hline 4 & 4 & 2000 \\
\hline 5 & 5 & 2500 \\
\hline 6 & 6 & 3000 \\
\hline 7 & 7 & 3500 \\
\hline 8 & 8 & 4000 \\
\hline 9 & 9 & 4500 \\
\hline 10 & 10 & 5000 \\
\hline
\end{tabular}

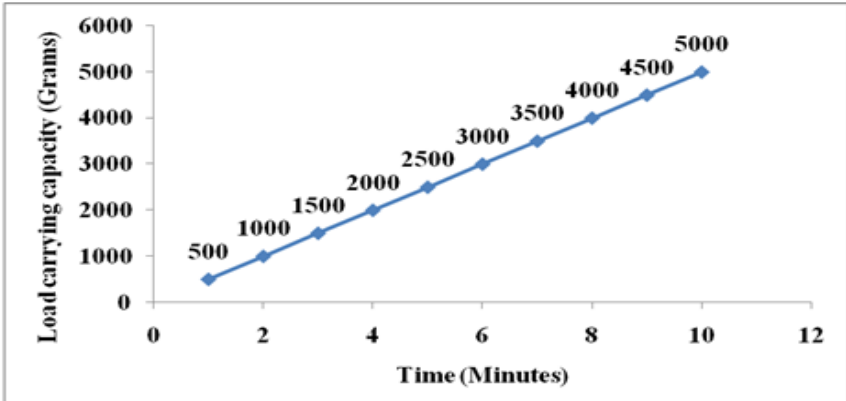

Figure 7: Gear head D.C. Motor with 30 R.P.M.

Table 8: Gear head D.C. Motor with 60 R.P.M.

\begin{tabular}{|l|l|l|}
\hline Observation No. & Time (Minutes) & Load carrying capacity (Grams) \\
\hline 1 & 1 & 1000 \\
\hline 2 & 2 & 1500 \\
\hline
\end{tabular}


Vishnu Datta Tiwari, and Prof. Gouraw Beohar

\begin{tabular}{|l|l|l|}
\hline 3 & 3 & 2000 \\
\hline 4 & 4 & 2500 \\
\hline 5 & 5 & 3000 \\
\hline 6 & 6 & 3500 \\
\hline 7 & 7 & 4000 \\
\hline 8 & 8 & 4500 \\
\hline 9 & 9 & 5000 \\
\hline 10 & 10 & 5500 \\
\hline
\end{tabular}

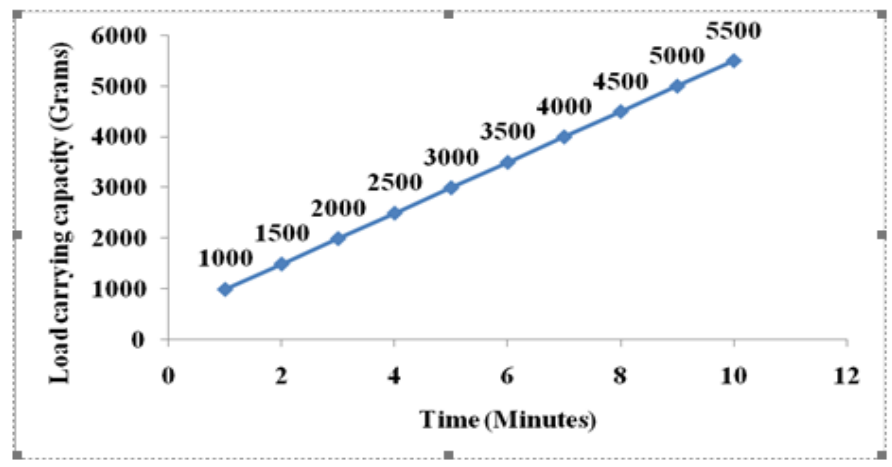

Figure 8: Gear head D.C. Motor with 60 R.P.M.

Table 9: Gear head D.C. Motor with 90 R.P.M.

\begin{tabular}{|c|c|c|}
\hline Observation No. & Time (Minutes) & Load carrying capacity (Grams) \\
\hline 1 & 1 & 1500 \\
\hline 2 & 2 & 2000 \\
\hline 3 & 3 & 2500 \\
\hline 4 & 4 & 3000 \\
\hline 5 & 5 & 3500 \\
\hline 6 & 6 & 4000 \\
\hline 7 & 7 & 4500 \\
\hline 8 & 8 & 5000 \\
\hline 9 & 9 & 5500 \\
\hline 10 & 10 & 6000 \\
\hline
\end{tabular}

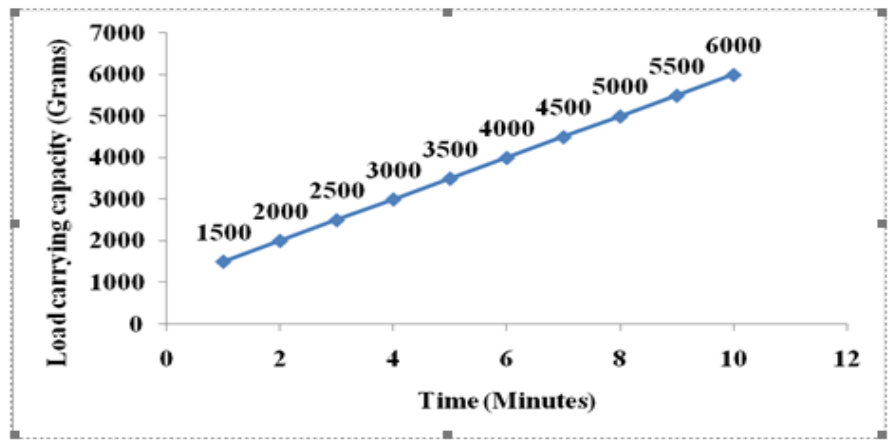

Figure 9: Gear head D.C. Motor with 90 R.P.M.

Table 10: Gear head D.C. Motor with 120 R.P.M.

\begin{tabular}{|c|c|c|}
\hline Observation No. & Time (Minutes) & Load carrying capacity (Grams) \\
\hline 1 & 1 & 2000 \\
\hline 2 & 2 & 2500 \\
\hline 3 & 3 & 3000 \\
\hline
\end{tabular}


Experimental Study and Design of Flat Belt Conveyer System with Different R.P.M.

\begin{tabular}{|c|c|c|}
\hline 4 & 4 & 3500 \\
\hline 5 & 5 & 4000 \\
\hline 6 & 6 & 4500 \\
\hline 7 & 7 & 5000 \\
\hline 8 & 8 & 5500 \\
\hline 9 & 9 & 6000 \\
\hline 10 & 10 & 6500 \\
\hline
\end{tabular}

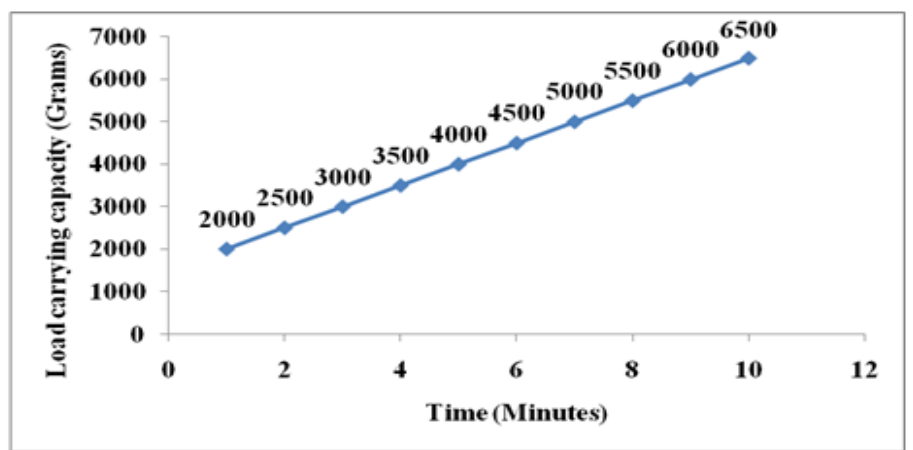

Figure 10: Gear head D.C. Motor with 120 R.P.M.

Table 11: Gear head D.C. Motor with 120 R.P.M.

\begin{tabular}{|c|c|c|}
\hline Observation No. & Time (Minutes) & Load carrying capacity (Grams) \\
\hline 1 & 1 & 2500 \\
\hline 2 & 2 & 3000 \\
\hline 3 & 3 & 3500 \\
\hline 4 & 4 & 4000 \\
\hline 5 & 5 & 4500 \\
\hline 6 & 6 & 5000 \\
\hline 7 & 7 & 5500 \\
\hline 8 & 8 & 6000 \\
\hline 9 & 9 & 6500 \\
\hline 10 & 10 & 6500 \\
\hline
\end{tabular}

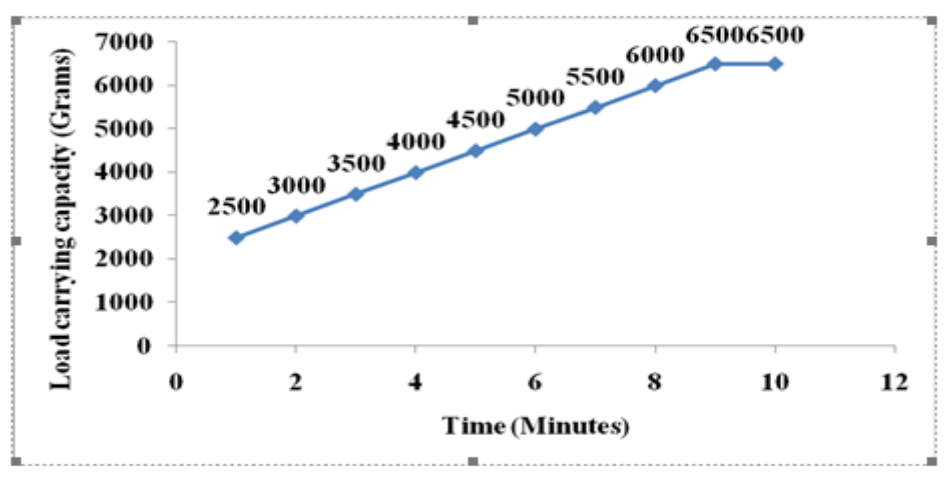

Figure 11: Gear head D.C. Motor with 120 R.P.M.

\section{CONCLUSION AND FUTURE SCOPE}

\subsection{CONCLUSION}

In this study, we found that different load capacity in grams from 500 to 6500 grams at different working hours in Hours with different R.P.M. such as 30, 60, 90, 120 and 150 R.P.M. using 12 V. D.C. motor, which has $10 \mathrm{KgF}$. It is 
verified that the material handling process of 6,500 grams has stability in the time of 9 to 10 minutes of adequate operation of the drive system during the rotation of the Gear of the DC motor has 120 RPM, which is shown in Table 11. Concludes maximum material capacity is 6,500 grams with constant DC motor speed of 120 RPM.

\subsection{FUTURE SCOPES}

1) To study about material handling using chain drive system.

2) To study and analysis about material handling using gear drive system with heavy load.

\section{SOURCES OF FUNDING}

This research received no specific grant from any funding agency in the public, commercial, or not-for-profit sectors.

\section{CONFLICT OF INTEREST}

The author have declared that no competing interests exist.

\section{ACKNOWLEDGMENT}

None.

\section{REFERENCES}

[1] S. M. Jadhav research paper on "Redesigning \& Optimization of Conveyor Pulley", Volume IV, Issue XII, December 2015.

[2] Pravin A. Mane research paper on "Design, Manufacture and Analysis of Belt Conveyor System used for Cooling of Mould" Vol. 2, Issue 3, May-Jun 2012, pp.2162-2167.

[3] Kasi Visweswarao research paper on "Design and selecting the proper conveyor belt" Ananth et al., International Journal of Advanced Engineering Technology.

[4] Molnár, Vieroslav, et al. "Analysis of asymmetrical effect of tension forces in conveyor belt on the idler roll contact forces in the idler housing." Measurement52 (2014): 22-32. 